\title{
Venous Thromboembolic Diseases: Risk and Etiological Factors in the Internal Medicine Department of the Sylvanus Olympio University Hospital in Lomé
}

\author{
Edem Komi Mossi", Abdou Razak Moukaila, Dzidzonu Komi Nemi, Waina Kodjo, \\ Sodjehoun Apeti, Agbeko Kodjo Djagadou, Abago Balaka, Awalou Mohaman Djibril \\ Department of Internal Medicine, University Hospital Sylvanus Olympio of Lome, University of Lome, Lome, Togo

\section{Email address:} \\ edemmossi@gmail.com (E. K. Mossi),moukaila.razak@gmail.com (A. R. Moukaila), nemiomidzidzonu@gmail.com (D. K. Nemi),

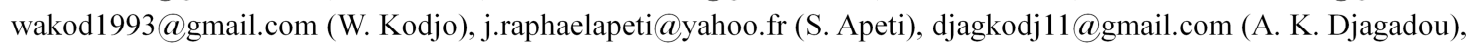 \\ francisabago@gmail.com (A. Balaka),m_djibril2000@yahoo.fr (A. M. Djibril) \\ *Corresponding author
}

\section{To cite this article:}

Edem Komi Mossi, Abdou Razak Moukaila, Dzidzonu Komi Nemi, Waina Kodjo, Sodjehoun Apeti, Agbeko Kodjo Djagadou, Abago Balaka, Awalou Mohaman Djibril. Venous Thromboembolic Diseases: Risk and Etiological Factors in the Internal Medicine Department of the Sylvanus Olympio University Hospital in Lomé. Clinical Medicine Research. Vol. 10, No. 1, 2021, pp. 16-19. doi: 10.11648/j.cmr.20211001.13

Received: January 6, 2021; Accepted: January 18, 2021; Published: January 25, 2021

\begin{abstract}
Introduction: Venous thromboembolic disease is a common condition. Many risk factors can contribute to its occurrence. The aim of this study is to describe the risk factors of venous thromboembolic diseases and the results of the etiological assessment. Methodology: This was a retrospective and descriptive study that took place in the internal medicine department of the Sylvanus Olympio University in Lomé, from January 1, 2016 to December 31, 2017. It included all patients of both sexes aged 18 and over hospitalized for deep vein thrombosis regardless of the site and / or documented pulmonary embolism. Results: We had collected 51 cases of venous thromboembolic disease. The mean age of the patients was $52.9 \pm$ 17.1 years with a male predominance $(52.9 \%)$. Deep venous thrombosis (DVT) of the lower limbs was the most frequent location (68.5\%). In our study, 59.3\% of patients presented at least one risk factor before any etiological assessment. No risk factor was found in nine patients (17.8\%). The main risk factors encountered were: obesity (17.6\%), HIV infection (13.7\%), diabetes (11.8\%), neoplasias (7.8\%), and prolonged bed rest (7.8\%). An etiology was found in $13.7 \%$ of cases, including 3 cases of thrombophilia and 4 cases of neoplasia. Conclusion: Obesity and HIV infection are the most common risk factors for venous thromboembolic diseases. Neoplasias are the most common etiologies after etiological investigation.
\end{abstract}

Keywords: Venous Thromboembolic Disease, Risk Factors, Etiologies, Lomé

\section{Introduction}

Venous thromboembolism disease (VTE) with its two clinical aspects (deep vein thrombosis and pulmonary embolism) is a common condition. The annual incidence of deep vein thrombosis (DVT) was estimated for both sexes at 1.6 per 1000 inhabitants [1], while that of pulmonary embolism with or without deep vein thrombosis was 23 per 100,000 inhabitants [1,2]. VTE represents a major public health issue due to its medium and long-term consequences and its high mortality rate [3]. In Côte d'Ivoire, the prevalence of deep vein thrombosis of the lower limbs was $3.1 \%$ in 2001
[4]. In Mali, the prevalence of lower limbs thrombophlebitis was estimated at $0.52 \%$ in 2005 [5]. Similarly, a study carried out in 2006 in Bamako revealed that pulmonary embolism represented $1.7 \%$ of all hospitalizations in the two cardiology departments of the Point $\mathrm{G}$ hospital [6]. In Togo the prevalence of VTE in hospitals was $3.1 \%$ [7].

Many risk factors, acquired or constitutional, may contribute to the emergence of VTE. The objective of this work is to identify the epidemiological and clinical profile of VTE in an internal medicine department in Togo by describing the epidemiological characteristics, risk factors as well as the etiologies of VTE. 


\section{Methodology}

This was a retrospective and descriptive study that took place over a period of two years from January 01, 2016 to December 31, 2017. It was carried out in the internal medicine department of the Sylvanus Olympio University Hospital in Lomé, the reference hospital in Togo's health system. Included were the records of patients of both sexes, aged 18 and over, hospitalized in the internal medicine department of the Sylvanus Olympio University Hospital in Lomé for deep vein thrombosis (DVT) regardless of location and / or documented pulmonary embolism (PE). The diagnosis of DVT and / or PE was evoked on the basis of clinical signs and confirmed by venous Doppler ultrasound and / or CT angiography. Patients hospitalized with suspicion of VTE not confirmed by medical imaging as well as patients with superficial venous thrombosis on venous Doppler ultrasound without deep network extension were excluded. Data collection was carried out in May 2018 and consisted of filling in a standardized information sheet for each patient based on the data in their medical file. This sheet included information on epidemiological, clinical and paraclinical data, risk factors for VTE and the results of the etiological assessment. The etiological factors were researched from data from the anamnestic survey, clinical examination and complementary examinations. All the data was recorded in data entry mask designed using Epidata 3.1 software. Statistical analysis was carried out using Release studio one 3.3.2 software. Qualitative variables were presented in the form of numbers and proportions and quantitative variables in the form of averages.

\section{Results}

We collected 51 VTE files. The male sex predominated (52.9\%) with a sex ratio $\mathrm{M} / \mathrm{F}$ of 1.13 . The mean age of the patients was $52.9 \pm 17.1$ years (range: 28 years and 92 years) and the age group most affected by VTE was between 35 and 44 years with $25.6 \%$ of the study population. The mean age of male patients was $55.9 \pm 15.1$ years (range: 28 and 83 years) and that of female patients was $49.61 \pm 9.0$ years (range: 29 and 92 years).

Thirty-five patients (68.6\%) had DVT of the lower limbs, and 10 patients $(19.6 \%)$ had pulmonary embolism (Table 1 ). Of the 35 cases of lower limb DVT, 31 (88.6\%) were unilateral, mostly involving the popliteal vein (48.4\%) and 4 $(11.4 \%)$ were bilateral. Concerning bilateral DVT, the contralateral limb had subclinical thrombosis and ultrasound discovery in three cases, all of which were prostate cancer patients; the fourth case was a toggle thrombosis in a person living with HIV (PLWHIV) in whom the thrombophilia assessment showed an isolated deficiency of protein $\mathrm{S}$. The pulmonary embolism was bilateral in $90 \%$ of cases and proximal in $50 \%$ of cases. DVT and PE were associated in 4 patients, 2 of whom had prostate neoplasia. The mean age of patients with DVT was $54.2 \pm 16.3$; of whom 17 (48.6\%) were male. Patients with PE had a mean age of $53.3 \pm 21.6$; of these $9(90 \%)$ were male. Thrombosis involving the jugular vein, utero-ovarian vein and cerebral veins, were all recorded in female patients. Four patients $(7.8 \%)$ presented a recurrence of DVT.

The main risk factors for VTE found were: obesity, HIV infection, diabetes; prolonged bed rest and cancer (Table 2). The thrombotic risk that these factors confer is not the same. They are therefore classified as major, moderate and minor FDRs. In our study, $56.9 \%$ of patients had at least one major RDF (Table 3). No risk factor was found in nine patients $(17.8 \%)$. Four patients $(7.8 \%)$ had multiple risk factors at the same time: the first female patient aged 66 years, had a combination of non-Hodgkin's malignant lymphoma, HIV infection and diabetes. The second male, aged 71, had diabetes, venous insufficiency and was immobilized for decompensation of heart failure. The third, an overweight female, was immobilized following recent surgery. The last patient was using oral contraceptives, was deficient in protein $\mathrm{C}$ and $\mathrm{S}$, and had recently taken a long trip. The etiological assessment carried out allowed us to find 3 cases of thrombophilia and 4 cases of neoplasia. The thrombophilia assessment was prescribed to 23 patients and carried out by 12 patients. In these patients, protein $\mathrm{C}$ and $\mathrm{S}$, antithrombin III were measured and anti-phospholipid antibodies were tested. We found a combined protein $\mathrm{C}$ and $\mathrm{S}$ deficiency in a 40-year-old patient with recurrent DVT; an isolated protein C deficiency in the assessment of cerebral thrombophlebitis in a 35-year-old patient and an isolated protein S deficiency in a person living with HIV with tilting venous thrombosis. Neoplasia was found in 4 patients (7.8\%) including 03 cases of prostate neoplasia.

Table 1. Distribution of patients by thrombosis topography of $(n=51)$.

\begin{tabular}{lll}
\hline & Effective (n) & Percentage (\%) \\
\hline Lower limb DVT & 35 & 68,6 \\
Pulmonary embolism & 10 & 19,6 \\
Thrombosis of the right jugular vein & 2 & 3,92 \\
Cerebral venous thrombosis & 2 & 3,92 \\
Utero-ovarian DVT & 1 & 1,96 \\
Upper limb DVT & 1 & 1,96 \\
DVT: Deep vein thrombosis & & \\
\hline
\end{tabular}

Table 2. Risk factors for VTE.

\begin{tabular}{lll}
\hline & Effective (n) & Percentage (\%) \\
\hline Medical & & \\
Obesity & 9 & 17,6 \\
HIV infection & 7 & 13,7 \\
Diabetes & 6 & 11,8 \\
Prolonged bed rest & 4 & 7,8 \\
Neoplasia & 4 & 7,8 \\
Venous insufficiency & 2 & 3,9 \\
Recent trip & 2 & 3,9 \\
Thrombophilia & 2 & 3,9 \\
Heart failure & 1 & 1,4 \\
Surgical & & \\
Recent surgery & 2 & 3,9 \\
Fracture & 1 & 1,9 \\
Gyneco-obstetrics & & \\
Hormonal contraception & 2 & 3,9 \\
Miscarriages & 1 & 1,9 \\
\hline
\end{tabular}


Table 3. Distribution of patients according to VTE level of risk.

\begin{tabular}{lll}
\hline & Effective (n) & Percentage (\%) \\
\hline Major risk & 30 & 86,4 \\
Age $>$ 60 years old & 16 & 31,4 \\
Neoplasia & 4 & 7,8 \\
Background of VTE & 4 & 7,8 \\
Thrombophilia & 3 & 5,9 \\
Recent surgery & 2 & 3,9 \\
Decompensated heart failure & 1 & 1,9 \\
Moderate risk & 1 & 1,9 \\
Plaster / trauma & 1 & 1,9 \\
Minor risk & 6 & 11,7 \\
Prolonged bed rest & 4 & 7,8 \\
Recent trip & 2 & 3,9 \\
\hline
\end{tabular}

\section{Discussion}

The objective of our work was to describe the risk factors for VTE and the results of the etiological assessment. We found a male predominance, which is in contradiction with the data in the literature $[8,9]$. The mean age of the patients was $52.9 \pm 17.1$ years (range: 28 years and 92 years). The mean age of venous thrombosis occurrence is relatively low in African subjects and varies between 40-48 years according to the literature $[10 ; 11]$. In contrast, the age of VTE occurrence is higher in western countries. In a study carried out in Spain, the average age was 65 years [12]. The majority of patients $(55 \%)$ in the study by Spencer et al. [13] were aged 65 years or over. This is explained by the fact that there is a positive correlation between age and the occurrence of a venous thromboembolic event. However, the relatively young age of our population could also be explained by the frequency of system diseases, which the etiological investigation did not look for in our study.

The risk factors were dominated by obesity (17.6\%), HIV infection (13.7\%), diabetes (11.8\%), prolonged bed rest $(7.8 \%)$ and neoplasia $(7.8 \%)$. Obesity is said to be an additive risk factor and not a risk factor in its own right [14]. It is responsible for reduced mobility and associated with a reduction in fibrinolytic activity, and could therefore increase the risk of postoperative DVT. HIV infection affected $13.7 \%$ of patients. Pio et al. reported an $8.62 \%$ prevalence of PLWHIV in their series in 2014 [7]. According to Niakara et al, VTEs represent $3.8 \%$ of cardiovascular events during HIV infection [15]. Indeed, it multiplies the risk of venous thromboembolic disease by at least 10 [16]. Prolonged bed rest for various reasons was found in $7.8 \%$ of cases. Based on pathophysiological arguments, immobilization was considered to be a risk factor for VTE. Thus, the lying position, can lead to muscular and diaphragmatic dysfunction, which reduces venous flow in the legs and causes venous stasis. This stasis, in turn, can induce a state of hypercoagulability by activating the extrinsic pathway of coagulation through hypoxemia, by the production of endothelial lesions or by reducing fibrinolytic activity [17]. The occurrence of VTE in bedridden patients who have benefited from thromboprophylaxis could be explained by: either an unknown predisposing ground, or an ineffectiveness or poor quality of the anticoagulants benefited by these patients. Coagulation abnormalities only affected $5.9 \%$ of patients in our study. This rate, which is lower than that found in other studies [18, 19], does not reflect the reality, as the exploration of these factors remains very limited to date due to the inadequacy of the technical facilities and the high cost of laboratories able to carry out these analyzes in our context. Thus, it would be erroneous to say that constitutional factors are rare in black people, because Houenassi et al, in a systematic search for protein $\mathrm{C}$ deficiency in VTE patients in Cotonou, found a prevalence of 9.3\% [20] while Konin et al observed an antithrombin III deficiency in half of the VTE patients in their study [21]. Moreover, these anomalies were highlighted in our study in patients with particular profiles, especially: a recurrence of DVT in a 40-year-old woman; an unusual cerebral site in a 35 -year-old woman; a tilting thrombosis in a 46-year-old PLWHIV in whom a protein S deficiency was detected. These data, on the one hand, agree with those in the literature concerning the profile of patients in whom the assessment of thrombophilia is indicated; and on the other hand underline the interest of looking for a protein $\mathrm{S}$ deficiency in a PLWHIV in front of DVT, given that this association is frequent [22].

A completely silent cancer can result in venous thromboembolic accidents as its first manifestation. Certain venous thromboses may at first sight appear suspicious because of their atypical location or their recurrent, migratory or bilateral nature. The prevalence of neoplasia in our study was $7.8 \%$. Pio et al [7] found a prevalence of $8.62 \%$ in his series in 2014. No risk factor was found in nine patients $(17.8 \%)$. This rate, which is lower than that of Diedhiou et al (20\%) [23] would probably be linked to the lack of a technical platform enabling better exploration of the etiologies [24], but also to the existence of occult pathologies such as cancers, as 5 to $10 \%$ of idiopathic VTEs reveal in the year following a cancer [25].

No assessment was requested in the search for systemic disease because most patients with idiopathic DVT were in their first episode and those with recurrence already had a known etiology.

\section{Conclusion}

VTE is a multifactorial pathology. The male sex predominated $(52.9 \%)$. The mean age of the patients was $52.9 \pm 17.1$ years and the age group most affected by VTE was between 35 years and 44 years. Most patients (68.6\%) presented with lower limb DVT

The majority (59.3\%) of patients presented at least one risk factor before any etiological assessment. The main risk factors for VDT found were: obesity, HIV infection, diabetes; prolonged bed rest and cancer. An etiology was retained in $13.7 \%$ of patients, dominated by prostate neoplasia. The occurrence of a thromboembolic event is therefore undoubtedly a warning sign in the search for cancer; especially that of the prostate especially if the patient is over 
40 years old. Carrying out an etiological assessment remains difficult in our context, on the one hand because of the insufficient technical platform, and on the other hand because of the lack of financial means and health insurance in most patients.

\section{Conflict of Interest}

All the authors do not have any possible conflicts of interest.

\section{References}

[1] Nordström M, Lindblad B, Bergqvist D, Kjellström T. A prospective study of the incidence of deep-vein thrombosis within a denned urban population. J Intern Med. 1992; 232 (2): 155-160.

[2] Anderson FA, Wheeler HB, Goldberg RJ et al. A population based perspective of the hospital incidence and case-fatality rates of deep vein thrombosis and pulmonary embolism: The Worcester DVT study. Arch Intern Med. 1991; 151 (5): 933938.

[3] Ferrari E, Jambou D, Fischer F, Appert-Flory A, Bayle J, M. Baudouy M. Venous thromboembolic disease in pregnant women. Sang Thrombose Vaisseaux. 1999; 11 (1): 16-21.

[4] Assi E. Contribution to the study of deep vein thrombosis in black Africans. Medicine Thesis. 2001, Abidjan.

[5] Diallo B A, Diall IB, Diakité S, Diakité M, Keita L, Ndirahisha E et al. Socio-epidemiological and evolutionary aspects of phlebitis of the lower limbs in Bamako. Afr. Ann. Thorac. Cardiovasc. Surg 2008; 3 (2): 66-69.

[6] Diall IB, Coulibaly S, Menta I, Ba Ho, Diakite M, Sidibe N et al Clinic and evolution of pulmonary embolism in 30 cases. Mali Medical. 2011; 26 (1): 3-6.

[7] Pio M, Baragou S, Afassinou Y, Atta S, Hachimou A, Ehlan K et al News on venous thromboembolic disease at the Sylvanus Olympio University Hospital in Lomé. J Rech Scien Univ Lome. 2013; 15 (1): 93-100.

[8] Denakpo J. L, Zoumenou E, Kerekou A, Dossou F, Hounton N, Sambieni $O$ et al Prevalence and characteristics of venous thromboembolic disease in women in a hospital setting in Cotonou. Med Afr Noire. 2012; 59 (3): 163-171.

[9] Baili L, Aydi Z, Dridi M, Ben Dhaou B, Boussema F, Rokbani L. Venous thrombosis in young subjects: about 105 cases. Rev Med Interne. 2013; 34 (1): 185- 186.

[10] Sangare I, Menta I, Ba HO, Fofana CA, Sidibe N, Sogodogo A. Thrombophlebitis of members in the Cardiology department of CHU Gabriel Toure.. Mali Med. 2015; 30 (1): 3-6.

[11] Zabsonre P, Nebie LVA, Soumandoulougou A, Samandoulougou A' Toguyeni JY' Kabore JP. CO 23 Venous thromboembolic disease in Ouagadougou: role of HIV infection. Ann Dermatol Venereol 2007; 134 (1): 40.
[12] Boulieu D, Ninet J, Pinede L, Didier-Laurent JF, Franco A. Early venous thrombosis of unusual site, in early pregnancy after ovarian hyperstimulation. Contracept Fertil Sex. 1989; 17 (1): 725-727.

[13] Spencer FA, Gore JM, Lessard D, Emery C, Pacifico L, Reed G. Venous thromboembolism in the elderly. A communitybased perspective. Thromb Haemost. 2008; 100 (5): 780-788.

[14] Anderson FA, Wheeler HB. Venous thromboembolism. Risk factors and prophylaxis. Clin Chest Med. 1995; 16 (2): 235251.

[15] Niakara A, Drabo YJ, Kambire Y, Nebie VA, Kabore NJP, Simon F. Cardiovascular attacks and HIV infection: study of 79 cases at the CHN in Ouagadougou (Burkina Faso). Bull Soc Pathol Exot. 2002; 95 (1): 23-26.

[16] Saber A, Aboolian A, Laraja R, Baron H, Hanna K. HIV/AIDS and the risk of deep vein thrombosis: a study of 45 patients with lower extremity involvement. Am Surg. 2001; 67 (7): 645-647.

[17] Pottier P, Hardouin JB, Lejeune S, Jolliet P, Gillet B, Planchon B. Immobilization and the risk of venous thromboembolism. A meta-analysis on epidemiological studies. Thromb Res. 2009; 124 (4): 468-476.

[18] Haslett C, Chilvers ER, Boon NA, Colledge NR, Hunter JAA. Internal medicine principles and practices. 2nd edition 2004. Davidson. Ed Maloine.

[19] Prandoni P. Prevention and treatment of venous thromboembolism with low molecular weight heparins: clinical implications of the recent European guidelines. Thrombosis journal. 2008; 6 (13): 1-5.

[20] Houenassi DM, Bigot A, Tchabi Y, VehounkpeSacca J, Akindes-DosssoYovo R, Gbaguidi L et al. Study of protein C deficiency in venous thromboembolic disease at the CNHU in Cotonou: study carried out in 54 black African patients living in Cotonou. Ann Cardiol Angeiol. 2013; 62 (1): 8-11.

[21] Diallo BA, Yena S, Diall IB, Diakite S, Sanogo K, Keita L et al. Phlebitis of the lower limbs in a Malian university hospital environment Afr. Ann. Thorac. Cardiovasc. Surg. 2008; 3 (2): 66-69.

[22] Konin C, Adoh M, Adoubib A, Anzouan-Kacou JB, Azagoh R, N'guetta $R$ et al. Unusual venous thrombosis indicative of human immunodeficiency virus infection and protein $\mathrm{S}$ deficiency. About two cases and review of the literature. Rev Med Interne. 2008; 29 (6): 508-511.

[23] Diedhiou D, Sarr A, Ndour-Mbaye N. M, Ka-Cisse M, Diop SN. Phlebitis of the lower limbs in internal medicine. Epidemiological, clinical and etiological aspects. About 40 cases in Dakar. Med. Afr. Noire. 2012; 59 (3): 172-176.

[24] Sevestre MA, Labarere J, Brin S, Carpentier P, Constant J, Degeilh $\mathrm{M}$ et al. Optimising histoty taking for evaluating the risk of venous thromboembolism: the OPTIMEV study. Journal des maladies vasculaires. 2005; 30 (4): 217-227.

[25] Meyer G. Venous thromboembolism and cancer. Rev Pneumol Clin. 2014; 70 (1-2): 91-94. 